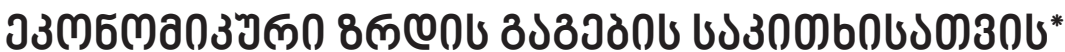

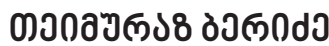

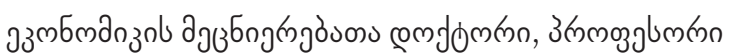

https://doi.org/10.35945/gb.2018.06.006

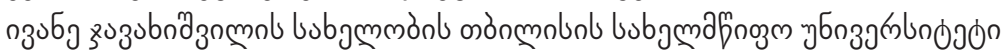

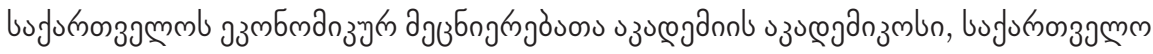

teimuraz.beridze@tsu.ge

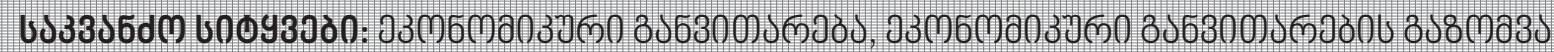

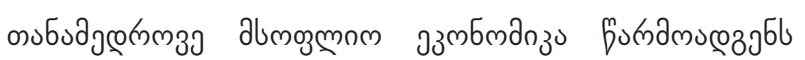

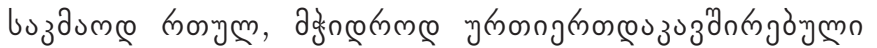

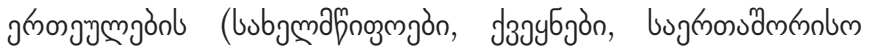

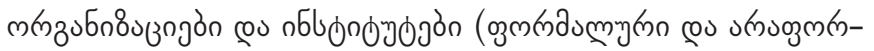

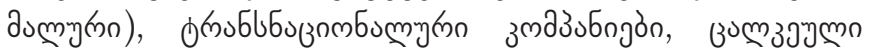

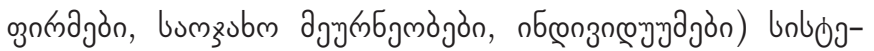

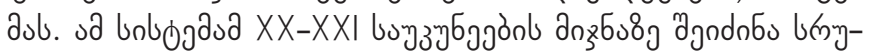

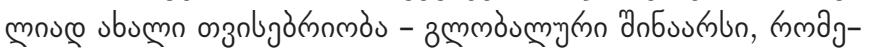

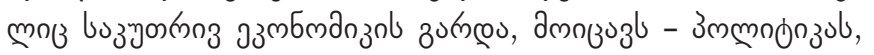

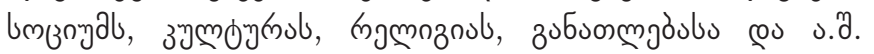

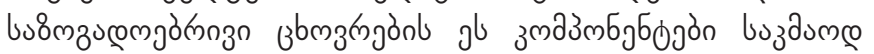

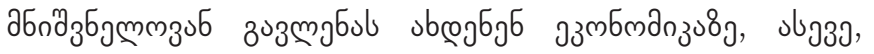
эзмбмдпзо абпдз

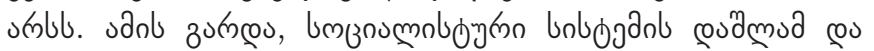

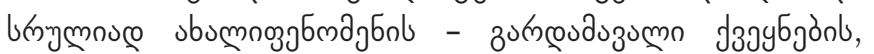

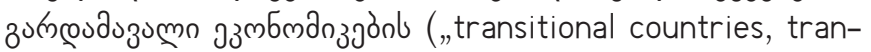

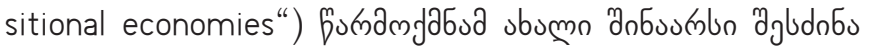

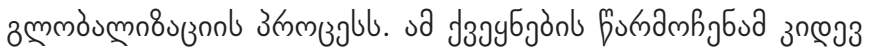

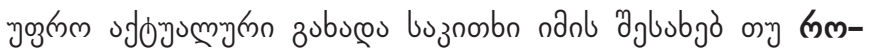

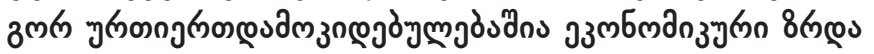

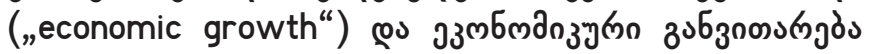

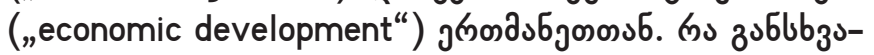

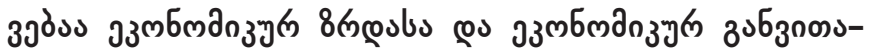

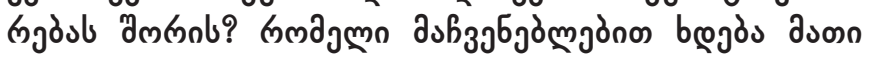

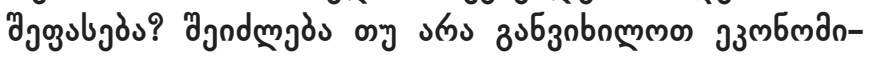

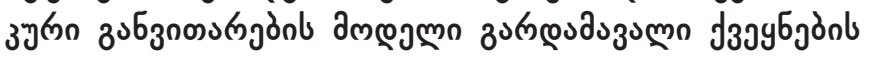

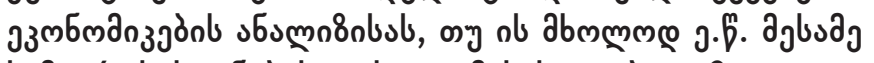

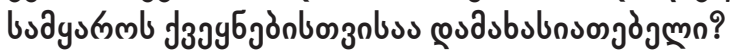

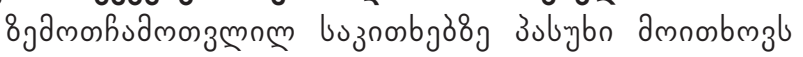

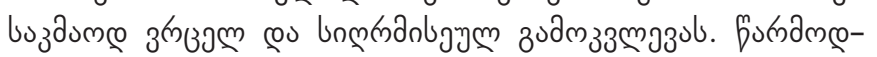

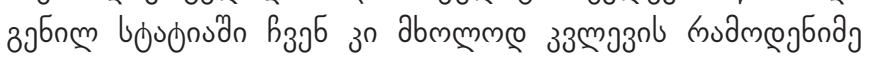

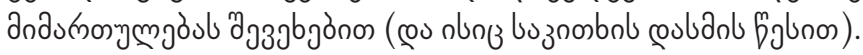

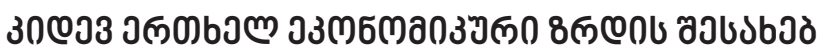

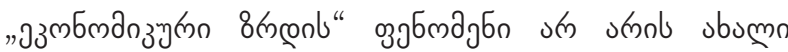

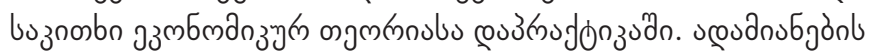

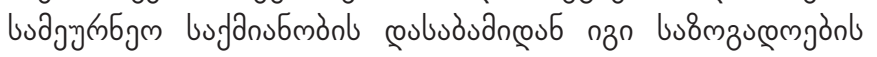

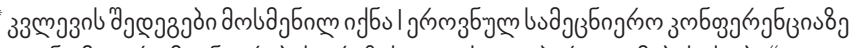

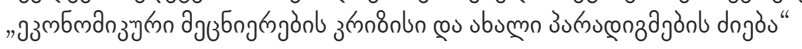

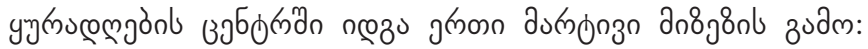

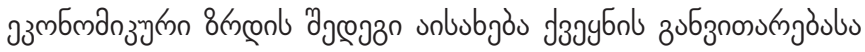

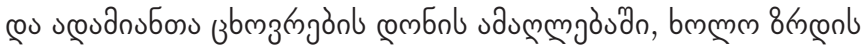

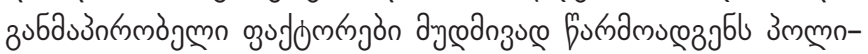

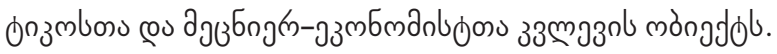

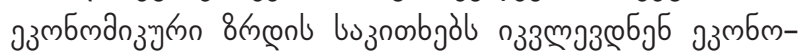

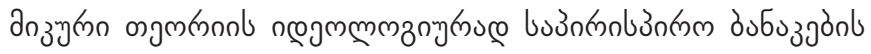
бumamau

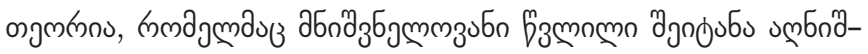

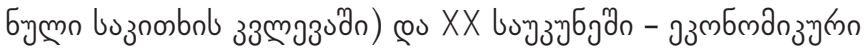

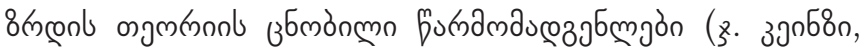

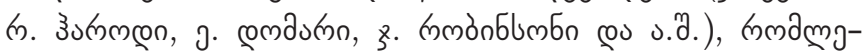

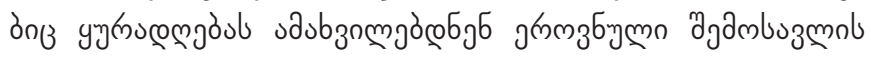

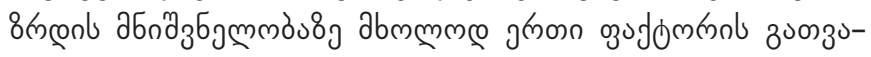

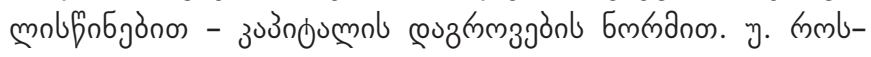

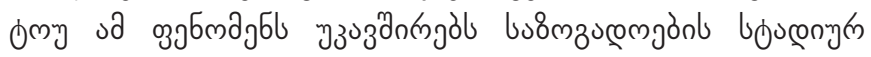

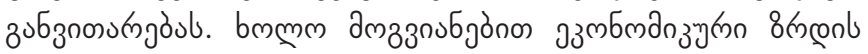

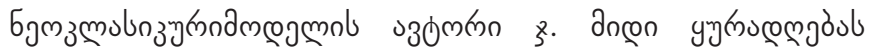

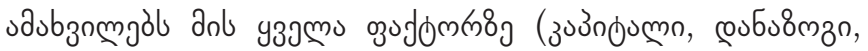

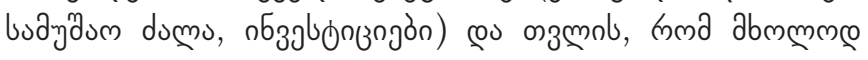

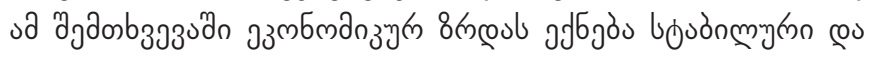
aegrinuen bulnuono.

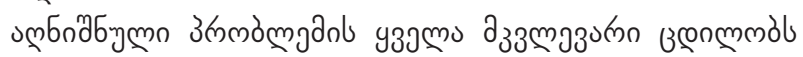

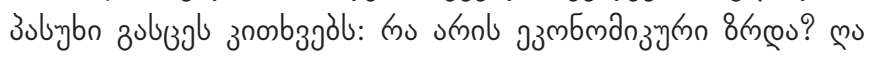

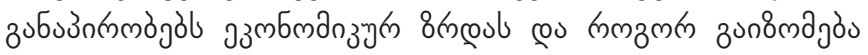

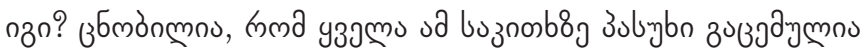

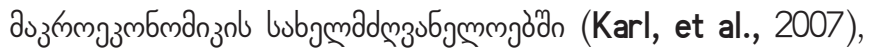

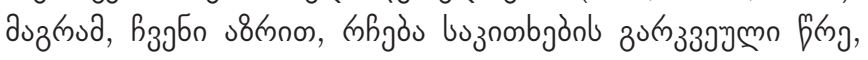

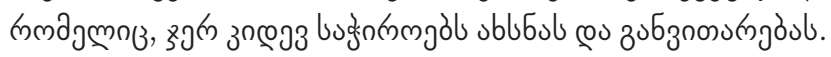

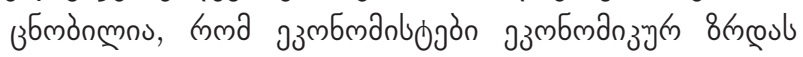

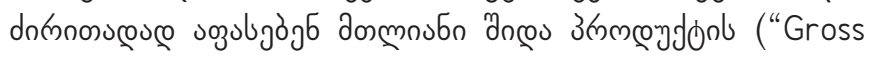

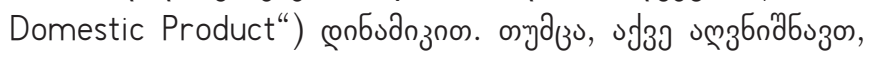

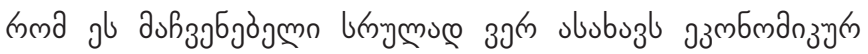

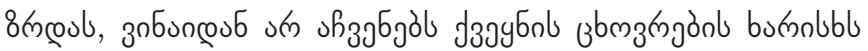

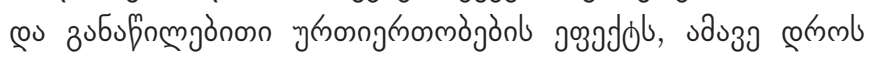

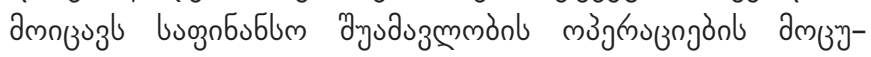

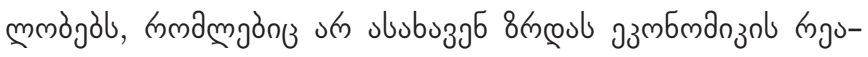

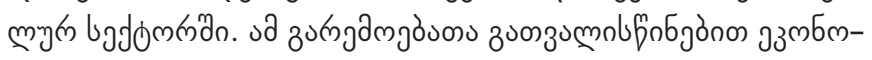

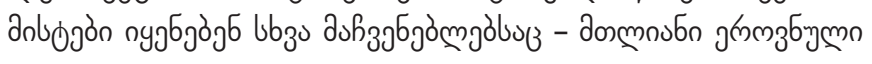




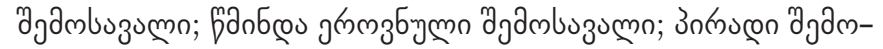

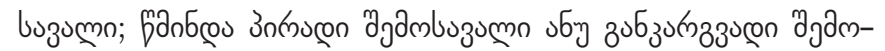

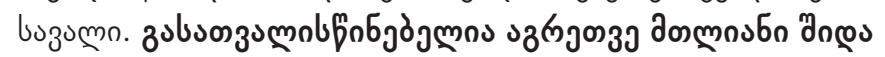

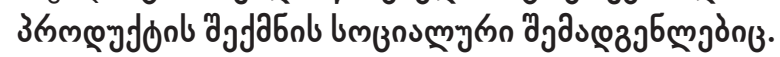

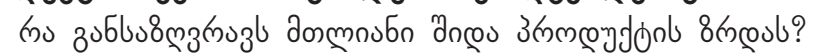

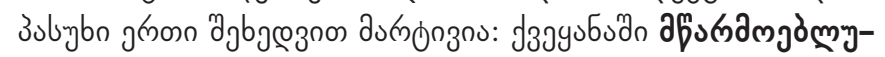

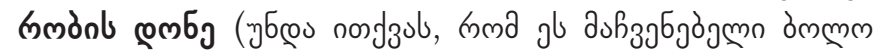

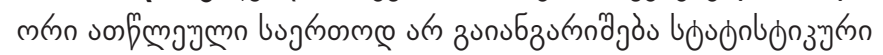

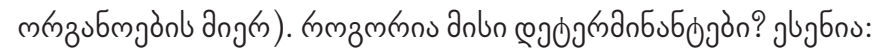

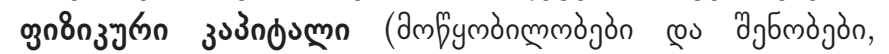

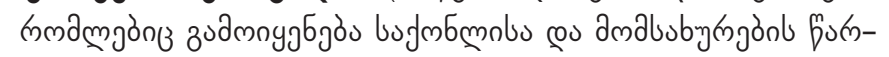

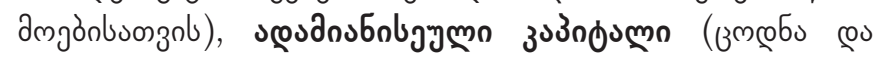

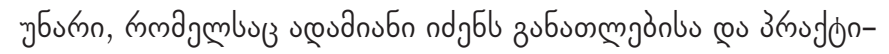

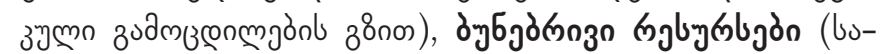

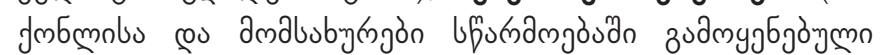

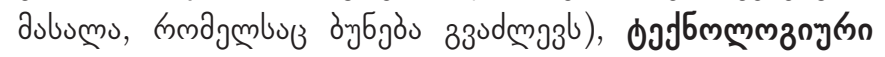

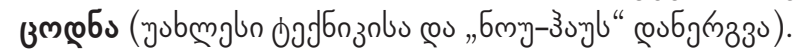

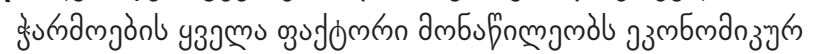

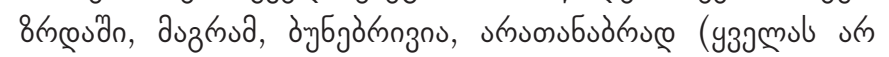

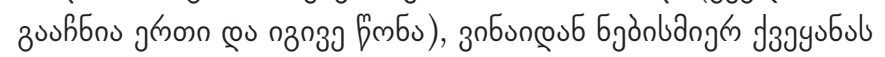
oلj

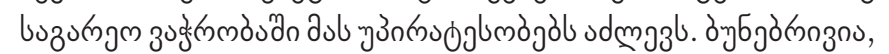

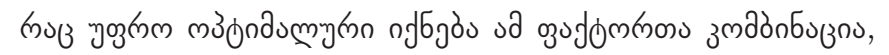

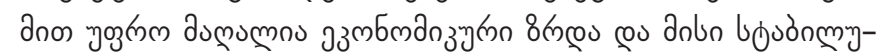

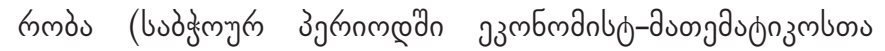

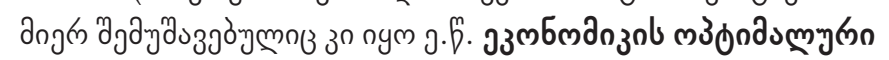

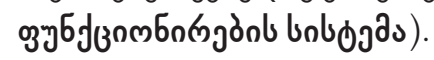

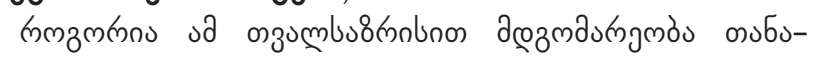

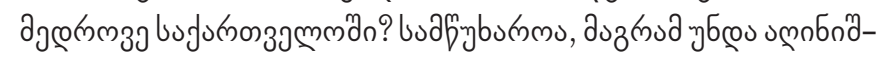

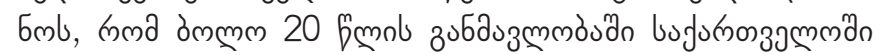

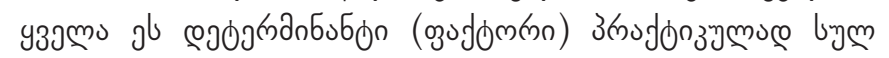

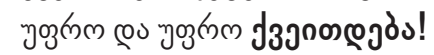

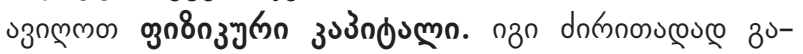

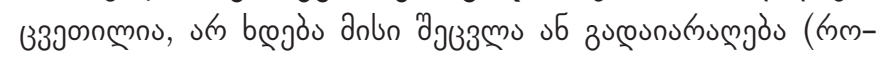

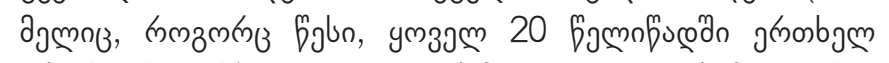

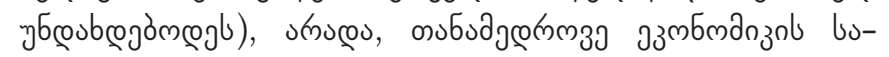

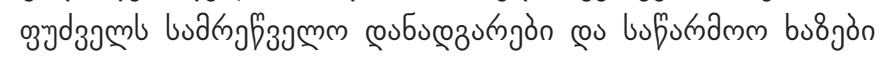

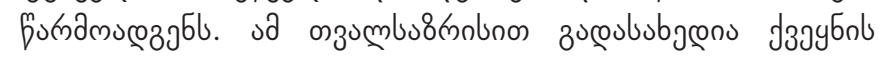

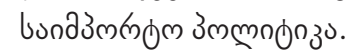

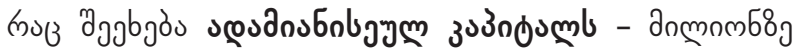

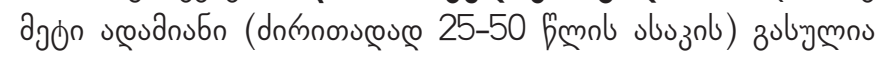

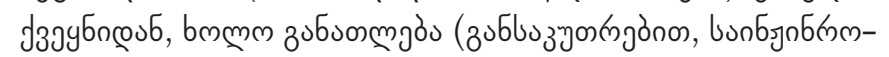

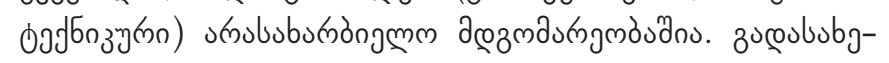

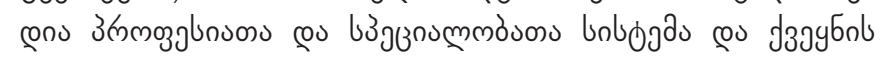

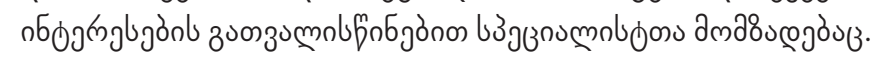

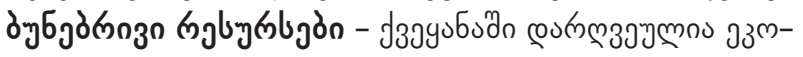

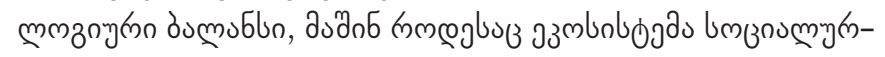

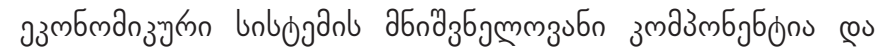

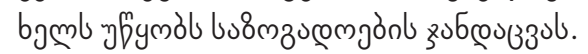

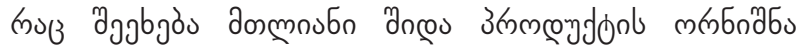

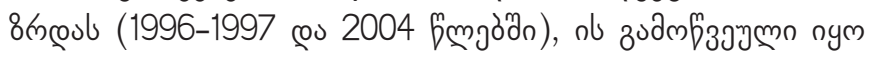

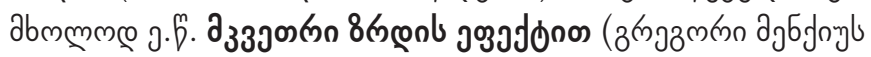

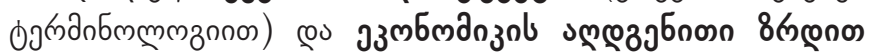

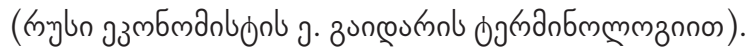

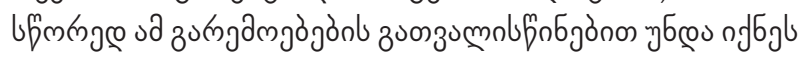

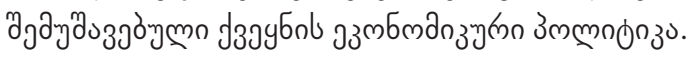

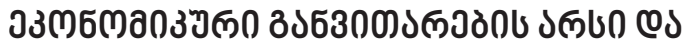

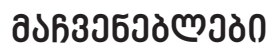

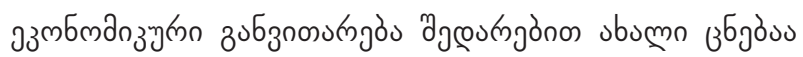

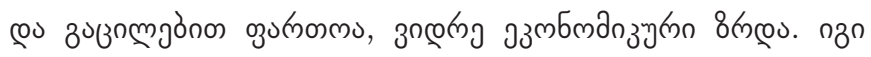
ububymno bubjmad

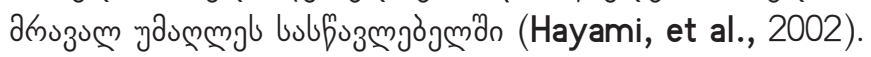

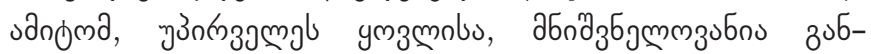

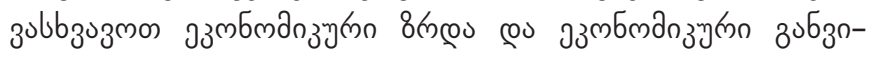

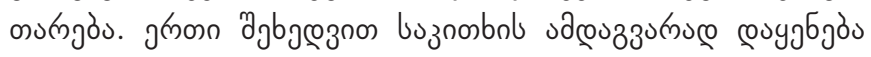

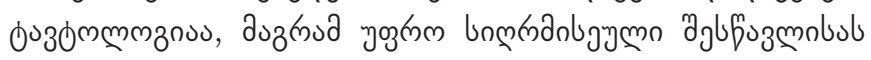

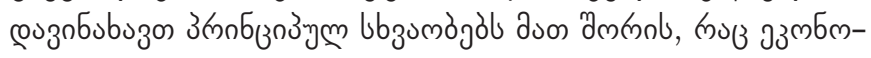

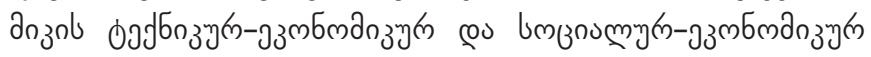

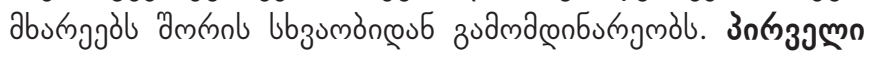

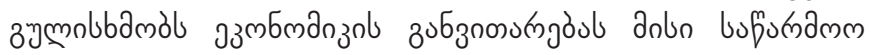

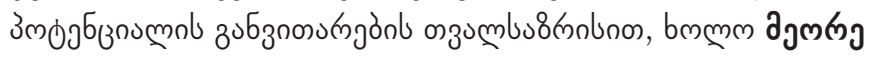

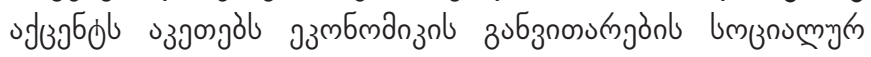

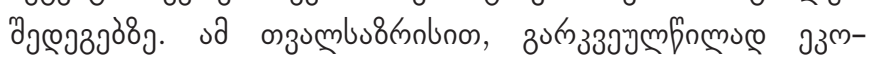

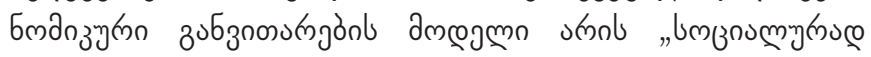

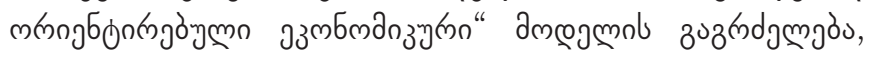

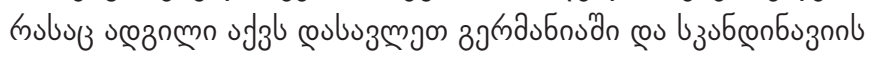

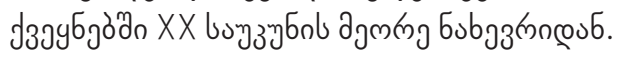

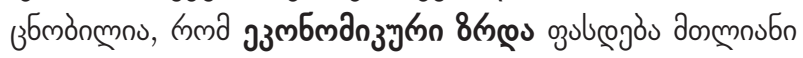

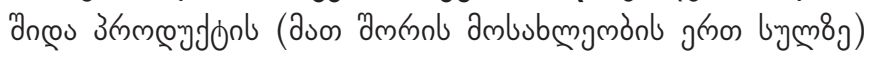

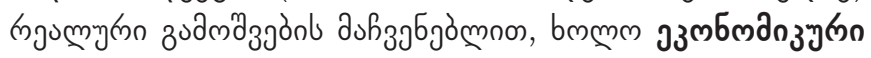

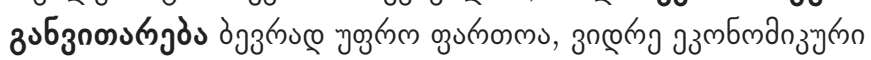

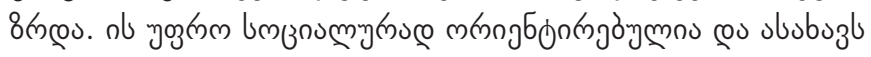

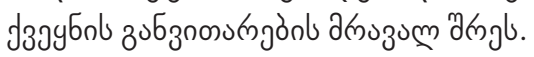

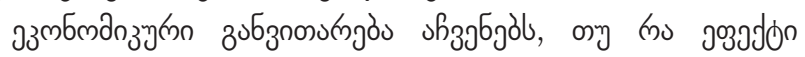

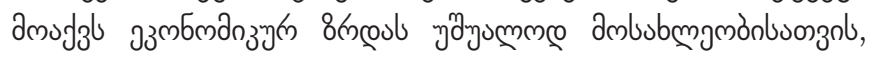

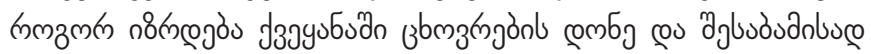

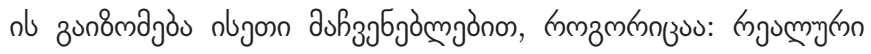

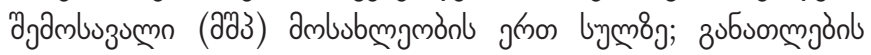

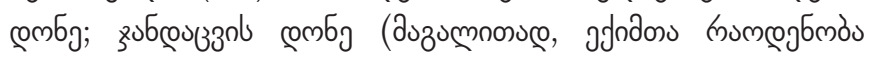

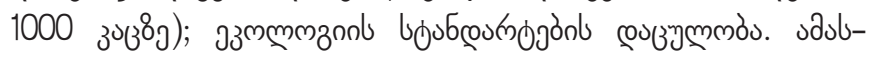

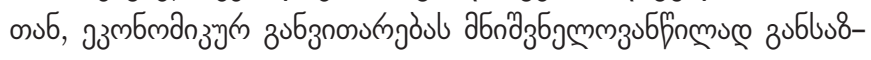

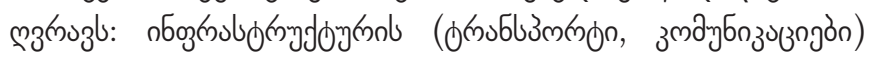

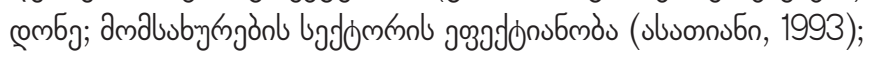

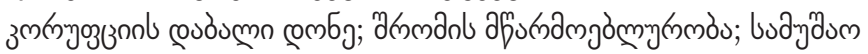

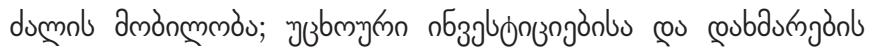

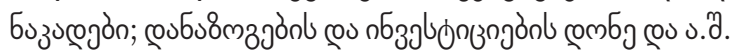




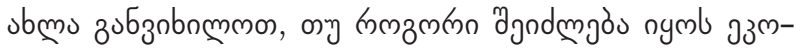

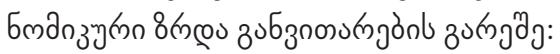

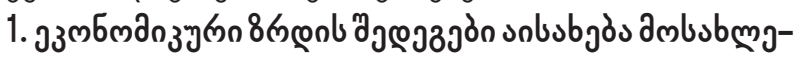

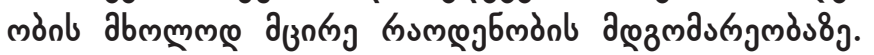

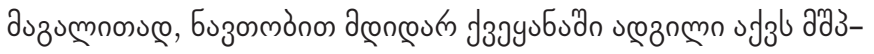

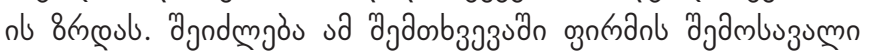

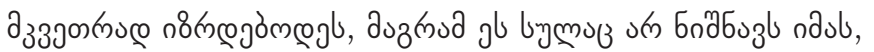

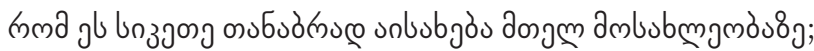

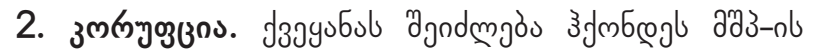

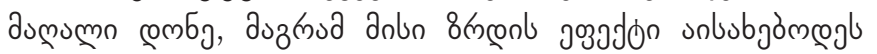

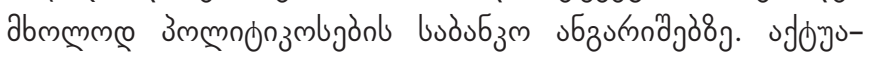

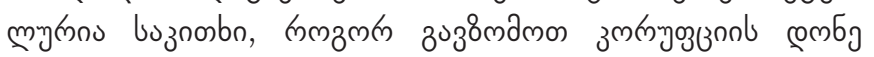

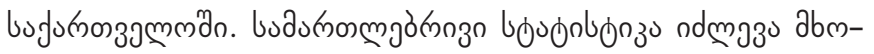

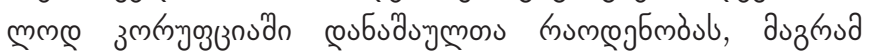

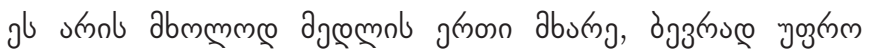

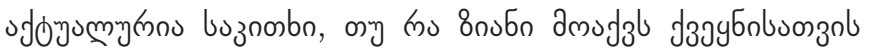

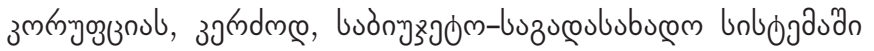
(Shevardnadze, et al., 2000);

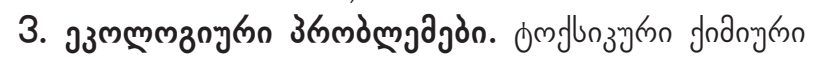

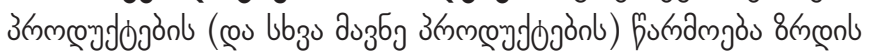

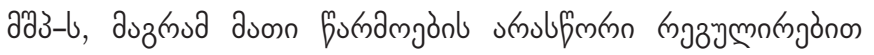

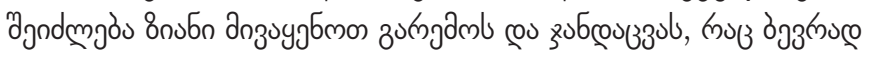

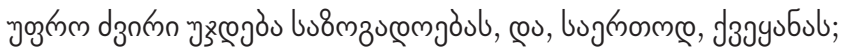

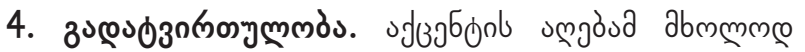

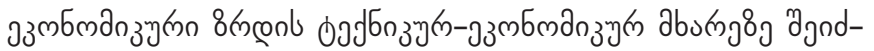

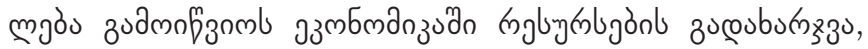

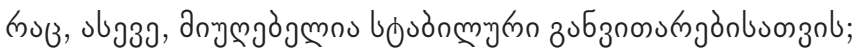

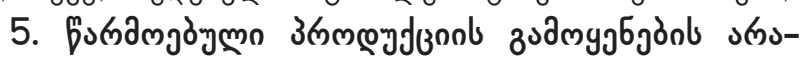

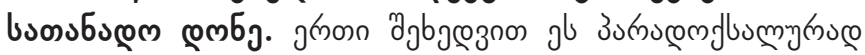

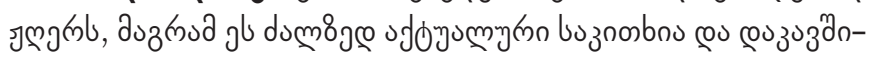

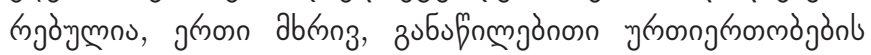

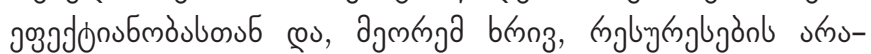
งе9з300

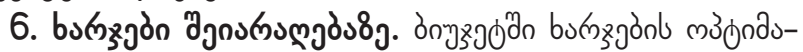

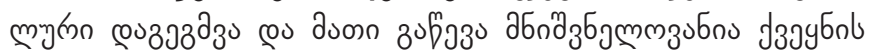

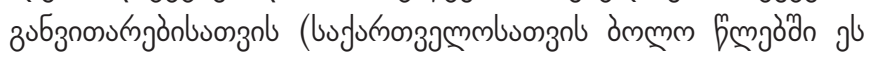

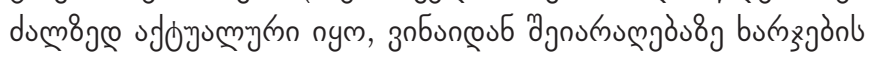

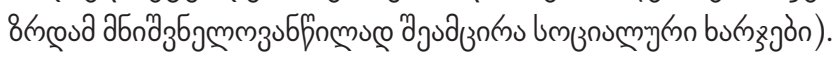

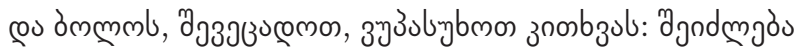

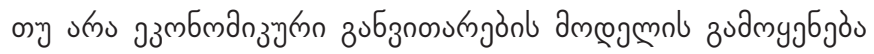

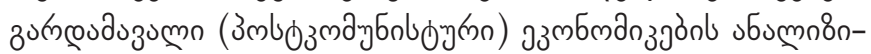

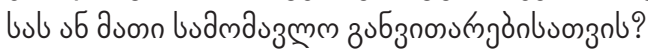

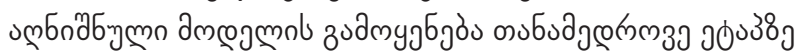

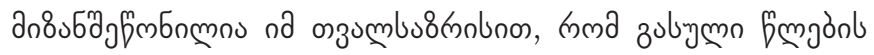

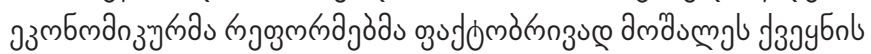

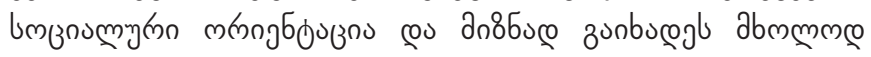

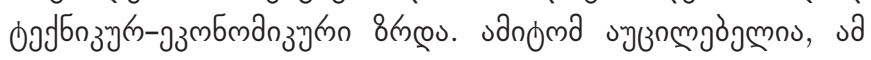

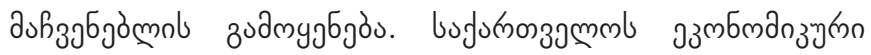

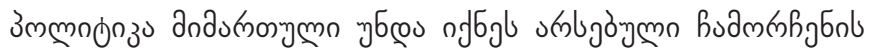
codmo3nbo3j6.

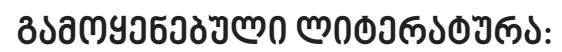

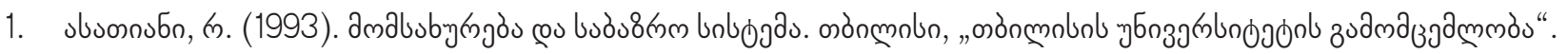

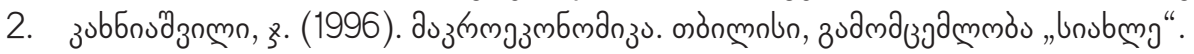

3. Karl E. Case, Ray C. Fair. (2007). Principles of Economics. Eighth Edition. Pearson Prentice Hall.

4. Hayami Y. and Godo Y. (2002). Development Economics. From the Poverty to the Wealth of Nations. Third Edition.

5. Kuznets S. (1971). - Prize Lecture to the memory of Al-fred Nobel. December 11, 1971. From Nobel Lectures, Economics 1969-1980, World Scientific Publishing Co., Singapore, 1992;

6. ShevardnadzeK., Chechelashvili R., Chocheli V., Khaduri N. (2000).Papava Indexes of Tax Corruption. Tbilisi, Publisher "Company Imperial Ltd.". 


\section{ON A QUESTION OF ECONOMIC GROWTH}

\section{TEIMURAZ BERIDZE}

https://doi.org/10.35945/gb.2018.06.006

Doctor of Economic Sciences, Professor

Ivane Javakhishvili Tbilisi State University,

Academician of the Academy of Economic Sciences of Georgia, Georgia

teimuraz.beridze@tsu.ge

\section{KEYWORD: ECONOMIC DEVELOPMENT, MEASURES OF ECONOMIC DEVELOPMENT}

\section{SUMMARY}

Economic development looks at a wider range than GDP per capita. Economic development is concerned with how people are actu-ally affected. It looks at their actual living standards and social condi-tions.

Measures of Economic development will look at: Real income per head - GDP per capita; Levels of literacy and edu- cation standards; Levels of healthcare (e.g. number of doctors per 1.000 popu-lation); Quality and availability of housing; Levels of environmental standards; Levels of infrastructure (transport, communication); Levels of corruption; Educational standards \& labor productivity; Labor mo-bility; Flow of foreign aid \& investment; Level of savings \& invest-ment; etc. 